\title{
Primary care utilization in people who experience imprisonment in Ontario, Canada: a retrospective cohort study
}

Fiona G. Kouyoumdjian ${ }^{1,2,3^{*}}$ (D), Stephanie Y. Cheng ${ }^{3}$, Kinwah Fung ${ }^{3}$, Stephen Humphreys-Mahaffey ${ }^{4}$, Aaron M. Orkin ${ }^{5,6,7}$, Claire Kendall ${ }^{3,8,9}$, Lori Kiefer ${ }^{7,10}$, Flora I. Matheson ${ }^{2,3,11}$, Samantha E. Green ${ }^{2,6}$ and Stephen W. Hwang ${ }^{2,3}$

\begin{abstract}
Background: Access to primary care is an important determinant of health, and data are sparse on primary care utilization for people who experience imprisonment. We aimed to describe primary care utilization for persons released from prison, and to compare utilization with the general population.

Methods: We linked correctional data for all persons released from provincial prison in Ontario, Canada in 2010 with health administrative data. We matched each person by age and sex with four general population controls. We compared primary care utilization rates using generalized estimating equations. We adjusted rate ratios for aggregated diagnosis groups, to explore this association independent of comorbidity. We examined the proportion of people using primary care using chi squared tests and time to first primary care visit post-release using the Kaplan-Meier method.

Results: Compared to the general population controls, the prison release group had significantly increased relative rates of primary care utilization: at 6.1 (95\% Cl 5.9-6.2) in prison, 3.7 (95\% Cl 3.6-3.8) in the week post-release and between 2.4 and 2.6 in the two years after prison release. All rate ratios remained significantly increased after adjusting for comorbidity. In the month after release, however, $66.3 \%$ of women and $75.5 \%$ of men did not access primary care.

Conclusions: Primary care utilization is high in prison and post-release for people who experience imprisonment in Ontario, Canada. Increased use is only partly explained by comorbidity. The majority of people do not access primary care in the month after prison release. Future research should identify reasons for increased use and interventions to improve care access for persons who are not accessing care post-release.
\end{abstract}

Keywords: Prison, Primary care, Healthcare utilization

\section{Background}

Worldwide, more than 10.3 million people are in prison at any given time [1], and an estimated 30 million people move through prisons annually [2]. On an average day, 37,864 persons in Canada and 2,217,000 persons in the USA are imprisoned in jails and prisons [1].

Given the increased morbidity and mortality experienced by this population [3], primary care in prison and

\footnotetext{
* Correspondence: kouyouf@mcmaster.ca

${ }^{1}$ David Braley Health Sciences Centre, McMaster University, 5th Floor, 100

Main Street West, Hamilton, Ontario L8P1H6, Canada

${ }^{2}$ St. Michael's Hospital, Toronto, Canada

Full list of author information is available at the end of the article
}

after prison release offers an important opportunity to improve health $[4,5]$. Further, States have obligations regarding the provision of health care to persons in prison, and to attend to aftercare at the time of prison release [6]. Comparing the health care utilization rates for people who experience imprisonment with rates for the general population is a strategy to assess health care accessibility as an indicator of health equity. For example, relatively low rates of primary care utilization would suggest worse access to care and highlight the need to facilitate primary care access to improve health status.

Studies from several countries have found increased primary care utilization for people while in prison and

(c) The Author(s). 2018 Open Access This article is distributed under the terms of the Creative Commons Attribution 4.0 International License (http://creativecommons.org/licenses/by/4.0/), which permits unrestricted use, distribution, and reproduction in any medium, provided you give appropriate credit to the original author(s) and the source, provide a link to the Creative Commons license, and indicate if changes were made. The Creative Commons Public Domain Dedication waiver (http://creativecommons.org/publicdomain/zero/1.0/) applies to the data made available in this article, unless otherwise stated. 
after release [5, 7-13]. In contrast, studies in the USA have identified relatively low use of primary care in prison and on release [14-17]. Current evidence is limited in internal and external validity, however, by small or select samples [15], the lack of general population comparator groups, $[5,8,9,11-17]$ use of self-reported data, [5, 12-17] and the age of data reported [8, 10]. Overall, there is a paucity of data on primary care use for this population, especially for the period after prison release, and no longitudinal studies have examined primary care utilization in prison and on release. In addition, we lack information on the ways in which factors such as comorbidity may contribute to increased health care utilization.

In the setting of a publicly funded universal health insurance system and a publicly funded and administered prison system, we aimed to describe the utilization of primary care for persons released from provincial prison in Ontario in 2010, and to compare primary care utilization for this group with the general population.

\section{Methods}

\section{Study design and setting}

We conducted a retrospective cohort study. We included all persons released from provincial correctional facilities in Ontario, Canada in 2010 as the exposed group and ageand sex-matched persons from the general population as the unexposed group. In Canada, provincial correctional facilities generally house persons who are admitted to prison prior to sentencing and who are sentenced to less than two years in prison [18]. We use the term "provincial prison" to represent all provincial correctional facilities, including jails and detention centres.

For Ontario residents (including Canadian citizens, permanent residents, Indigenous persons, and persons working full-time on a valid work permit, for whom Ontario is their primary residence), health care including hospitalizations, medically necessary surgeries, physician services including primary care, and medical tests are paid for through the public health insurance system, the Ontario Health Insurance Plan (OHIP) [19]. OHIP pays for health care provided in provincial prison and in the community, though additional health care costs are paid for in provincial prison, such as the cost of prescription medications.

In Ontario, provincial prisons are publicly funded and administered through the Ministry of Community Safety and Correctional Services (MCSCS). People in provincial prison access primary care routinely for an initial admission within weeks of admission or prior to this if medically indicated, and subsequently based on identified need for ongoing or episodic care by health care staff or through patient request. Physician employment arrangements vary across provincial prisons, but in general physicians are contracted by the ministry to provide on-site health services under OHIP. At some facilities, the contracted physician may hire additional physicians to work with them, and in a few other facilities the ministry contracts a private health service agency to recruit and contract physicians to provide services. Many physicians practice in the community as well as in a provincial prison.

\section{Study cohort}

For this study, the MCSCS provided identifying data on all persons 18 years old or older who were released from provincial prison in 2010, including name, date of birth, sex, self-reported race, and OHIP number. The MCSCS also provided dates of admission and release and reasons for release between 2005 and 2015. The MCSCS transferred these data to ICES, an independent, non-profit organization funded by the Ontario Ministry of Health and Long-Term Care, which houses health administrative data for Ontario residents.

As described previously [20], we linked data on persons released from provincial prison with an encoded health card number (IKN) in the Registered Persons Database, which is a comprehensive database of all persons in Ontario who are eligible for coverage through OHIP [19]. To link, we used the OHIP number when provided and valid. If the OHIP number was unavailable or invalid, we used a validated method to link people deterministically or probabilistically using name and date of birth [21]. We excluded linkages that were apparently invalid (Additional file 1). We limited the sample to persons released to the community in 2010 (Additional file 1) since we were interested in access to primary care in the community post-release; we called this the prison release group.

For each person in the prison release group, we randomly selected four persons from the Registered Persons Database as general population controls from the full list of persons who had the same age and sex and were eligible for OHIP on the date of release of the person in the prison release group. We chose to match on age and sex since these factors are strongly associated with health care utilization $[22,23]$. We used a ratio of $4: 1$ for matching to optimize statistical efficiency [24], without replacement (i.e. each person could be selected as a control only once).

\section{Variables}

\section{Socio-demographic information}

For each person using the postal code at the time of admission to prison, we accessed data on neighbourhood income quintile (and categorized the data as missing or by quintile) and residence in rural areas/small towns (and categorized the data as missing or residence in rural area/small town or not). We used self-reported 
race from the MCSCS data; we maintained the category names provided by the MCSCS, e.g. "Aboriginal" for Indigenous persons.

\section{Comorbidities}

We applied previously validated algorithms [25-30] to define the proportion of persons with a prior diagnosis of the following chronic conditions: diabetes, hypertension, chronic obstructive pulmonary disease (COPD), asthma, congestive heart failure (CHF), and HIV infection. We applied definitions from the Ontario Mental Health and Addictions Scorecard and Evaluation Framework to identify persons with mood disorders, schizophrenia, substance-related disorders, and anxiety disorders [31]. To describe overall morbidity burden, we used the Johns Hopkins Adjusted Clinical Group (ACG) system [32]; for each person, we determined the number of Aggregated Diagnosis Groups (ADGs), which are 32 diagnosis clusters that indicate the burden of disease comorbidity [33]. For the mental illness diagnosis and ADGs, we used data for the two years prior to the date of initial release from provincial prison in 2010 or the corresponding date for general population controls.

\section{Outcome}

We defined primary care as visits to general practitioners or Family Physicians, whether in walk-in clinics or community practices. We accessed data in the OHIP database for visits for which the specialty code was " 00 ," which is the code for a general practitioner or Family Physician, and for which "office" was specified as the location. We excluded laboratory records and claims from nonmedical practitioners. We considered claims by the same physician for the same patient on the same day to be a single health encounter.

\section{Analysis}

We right censored the period of follow up post-release at the earliest of death, loss of OHIP eligibility, re-admission to provincial prison (for persons released from provincial prison), or two years post-release (or corresponding date in the general population controls). We calculated person-time as the number of days in each period under study. We calculated the primary care utilization rate as the number of primary care encounters divided by person-time at risk. We calculated primary care utilization by period relative to the time in prison, i.e. in prison and days 0-6, 7-29, 30-89, 90-179, 180-364, and 365-730 after the initial release in 2010. We selected these periods based on prior research regarding periods of risk of adverse outcomes on release from prison, including hospitalization and death, and given our specific interest in access to primary care in the immediate post-release period as an indicator of continuity of care [20, 34-36].

We calculated rate ratios for primary care utilization for the prison release group compared to general population controls. We used generalized estimating equations with a negative binomial model, in which we controlled for correlation due to matching. We decided a priori to adjust for neighbourhood income quintile and rurality as potential confounders of the association between incarceration status and primary care utilization. Recognizing that comorbidity may function as an antecedent or mediating variable between imprisonment status and health care utilization, we further adjusted models for ADGs (as an indicator of comorbidity) to explore whether an association between imprisonment status and primary care utilization would persist [37].

We examined the proportion of persons in the prison release group and general population controls who accessed any primary care in each time period, and we compared the proportions between groups using chi squared tests.

We generated Kaplan-Meier curves for time to first use of primary care post-release to two years for the prison release group, stratified by sex.

For all analyses, we specified an alpha of 0.05 .

We developed a protocol a priori (available from the corresponding author on request). We made two changes to the protocol: we included four general population controls per person in the prison release group instead of one, and we used negative binomial instead of Poisson models based on the outcome distribution.

\section{Results}

Of 53,955 persons released from provincial prison in Ontario in 2010, we linked 52,546 (97.4\%) (Additional file 1). We excluded 233 persons who had a release period of 1 day or less in 2010, 2,178 persons transferred to federal custody on release, 7 persons whose reason for release was death, and 1,267 persons whose reason for release was related to immigration, leaving 48,861 persons in the prison release group. We identified four age and sex-matched general population controls for each person in the prison release group, for a total of 195,444 general population controls.

A larger proportion of those in the prison release group were in lower neighbourhood income quintiles and were from rural areas or small towns, compared to general population controls (Table 1). The median number of ADGs was significantly greater for the prison release group compared to controls. Persons in the prison release group also had a significantly higher prevalence of all conditions examined, except for hypertension.

For the prison release group, primary care utilization rates were highest while in prison (Fig. 1), with a substantial decrease in use at the time of release. 
Table 1 Characteristics of persons released from provincial prison in 2010 and age- and sex-matched general population controls in Ontario, Canada

\begin{tabular}{|c|c|c|c|c|c|}
\hline \multicolumn{3}{|l|}{ Characteristic } & \multirow{2}{*}{$\begin{array}{l}\text { Prison release group, } \\
N=48,861\end{array}$} & \multirow{2}{*}{$\begin{array}{l}\text { General population controls, } \\
N=195,444 \\
32(24-43)\end{array}$} & \multirow{2}{*}{$\frac{p \text { value }^{*}}{\text { N/A }}$} \\
\hline Age- n (\%) & Median $\left(\mid Q^{a}\right)$ & & & & \\
\hline \multirow[t]{2}{*}{ Sex-n (\%) } & Male & & $42,754(87.5 \%)$ & $171,016(87.5 \%)$ & $\mathrm{N} / \mathrm{A}$ \\
\hline & Female & & $6107(12.5 \%)$ & $24,428(12.5 \%)$ & \\
\hline \multirow[t]{5}{*}{ Self-reported race ${ }^{b}-\mathrm{n}(\%)$} & Missing & & $4,499(9.2 \%)$ & - & - \\
\hline & White & & $28,745(58.8 \%)$ & - & - \\
\hline & Black & & $5,568(11.4 \%)$ & - & - \\
\hline & Aboriginal & & $4,954(10.1 \%)$ & - & - \\
\hline & Other & & $5,095(10.4 \%)$ & - & - \\
\hline \multirow[t]{6}{*}{ Neighbourhood income quintile- n (\%) } & Missing & & $2,317(4.7 \%)$ & $1,009(0.5 \%)$ & $<.001$ \\
\hline & 1 (lowest) & & $18,151(37.1 \%)$ & $39,076(20.0 \%)$ & \\
\hline & 2 & & $10,481(21.5 \%)$ & $39,113(20.0 \%)$ & \\
\hline & 3 & & $7,706(15.8 \%)$ & $39,044(20.0 \%)$ & \\
\hline & 4 & & $5,923(12.1 \%)$ & $39,978(20.5 \%)$ & \\
\hline & 5 & & $4,283(8.8 \%)$ & $37,224(19.0 \%)$ & \\
\hline \multirow[t]{3}{*}{ Rural/Small Town- n (\%) } & Missing & & $1,573(3.2 \%)$ & $164(0.1 \%)$ & $<.001$ \\
\hline & Yes & & $6,339(13.0 \%)$ & $20,659(10.6 \%)$ & \\
\hline & No & & $40,949(83.8 \%)$ & $174,621(89.3 \%)$ & \\
\hline \multirow[t]{2}{*}{ Time in provincial prison- median days $\left(\mathrm{IQR}^{\mathrm{a}}\right)$} & \multicolumn{2}{|c|}{ Admission leading to initial 2010 release } & $10(3-52)$ & - & - \\
\hline & \multicolumn{2}{|l|}{ Past five years } & $72(12-230)$ & - & - \\
\hline Time to reincarceration- median days $\left(\mathrm{IQR}^{\mathrm{a}}\right)$ & & & $195(69-490)$ & - & N/A \\
\hline \multirow[t]{7}{*}{ Person years of follow up (persons) } & In prison ${ }^{c}$ & & $6,685(48,861)$ & $26,738(195,444)$ & N/A \\
\hline & Post-release ${ }^{c}$ & 0-6 days & $932(48,861)$ & $3,745(195,444)$ & \\
\hline & & 7-29 days & $2,929(47,870)$ & $12,299(195,393)$ & \\
\hline & & 30-89 days & $6,917(44,939)$ & $32,037(195,231)$ & \\
\hline & & 90-179 days & $8,960(39,328)$ & $47,921(194,794)$ & \\
\hline & & 180-364 days & $14,624(33,538)$ & $98,056(194,158)$ & \\
\hline & & 365-730 days & $23,251(26,055)$ & $192,449(193,040)$ & \\
\hline \multirow[t]{4}{*}{ Number of ADGs ${ }^{\mathrm{a}}-\mathrm{n}(\%)$} & Median (IQR) & & $4(2-7)$ & $3(1-5)$ & $<.001$ \\
\hline & $0-4$ & & $25,383(51.9 \%)$ & $136,412(69.8 \%)$ & $<.001$ \\
\hline & $5-9$ & & $17,395(35.6 \%)$ & $51,825(26.5 \%)$ & \\
\hline & $\geq 10$ & & $6,083(12.4 \%)$ & $7,207(3.7 \%)$ & \\
\hline \multirow[t]{5}{*}{ Chronic disease prevalence $^{\mathrm{d}}-\mathrm{n}(\%)$} & Diabetes & & $2,341(4.8 \%)$ & $8,047(4.1 \%)$ & $<.001$ \\
\hline & Hypertension & & $3,629(7.4 \%)$ & $17076(8.7 \%)$ & $<.001$ \\
\hline & $\mathrm{COPD}^{\mathrm{a}}$ & & $2178(4.5 \%)$ & $3960(2.0 \%)$ & $<.001$ \\
\hline & Asthma & & $8011(16.4 \%)$ & $26,939(13.8 \%)$ & $<.001$ \\
\hline & $\mathrm{CHF}^{\mathrm{a}}$ & & $166(0.34 \%)$ & $507(0.3 \%)$ & 0.002 \\
\hline \multicolumn{3}{|l|}{ HIV $^{\mathrm{a}}$ infection prevalence ${ }^{\mathrm{d}}-\mathrm{n}(\%)$} & $330(0.7 \%)$ & $343(0.2 \%)$ & $<.001$ \\
\hline \multirow[t]{4}{*}{ Mental disorders - n (\%)prevalence ${ }^{d}$} & \multicolumn{2}{|l|}{ Mood disorders } & $3,318(6.8 \%)$ & $1,521(0.8 \%)$ & $<.001$ \\
\hline & \multicolumn{2}{|l|}{ Schizophrenia } & $1,909(3.9 \%)$ & $696(0.4 \%)$ & $<.001$ \\
\hline & \multicolumn{2}{|l|}{ Anxiety disorders } & $3,757(7.7 \%)$ & $2,336(1.2 \%)$ & $<.001$ \\
\hline & \multicolumn{2}{|c|}{ Substance-related disorders } & $8,270(16.9 \%)$ & $2,392(1.2 \%)$ & $<.001$ \\
\hline
\end{tabular}

*For chi squared or $\mathrm{t}$ test. ${ }^{\mathrm{a}} \mathrm{IQR}$ interquartile range, ADGsAggregated Diagnosis Groups, COPD Chronic obstructive pulmonary disease, CHF congestive heart failure, HIV human immunodeficiency virus. ${ }^{b}$ Data on race were not available for the general population. We did not modify the category names provided by the MCSCS, e.g. Aboriginal. ${ }^{c}$ Or the corresponding dates for general population controls. ${ }^{d}$ Diagnosis based on health administrative data 


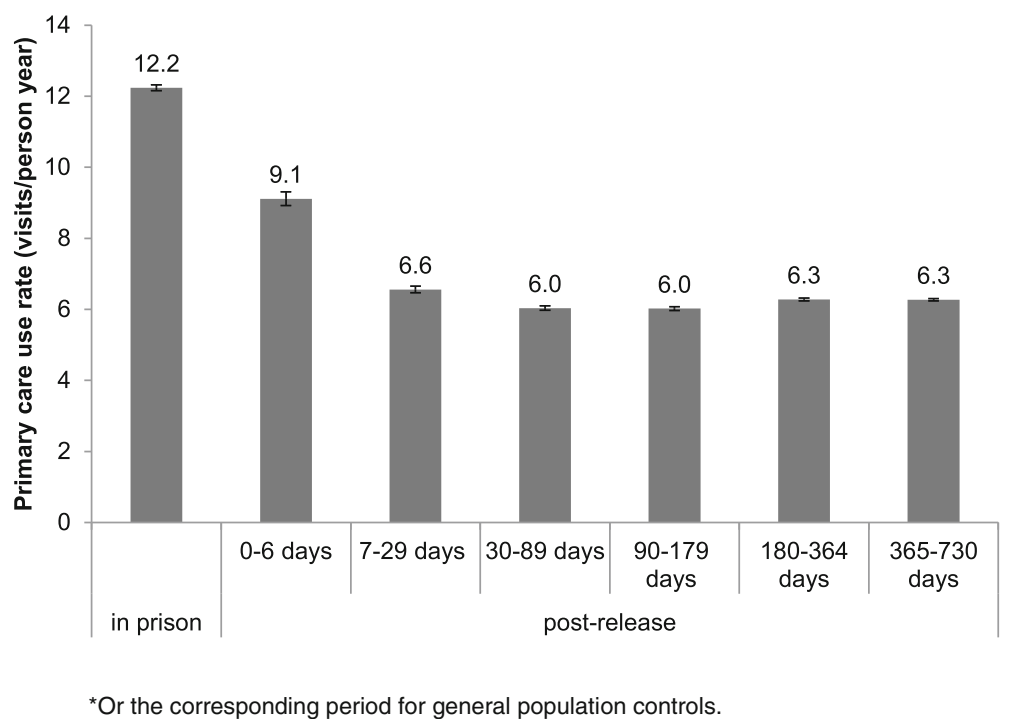

Fig. 1 Rates of primary care utilization and 95\% confidence intervals for persons released from provincial prison in 2010 in Ontario, Canada, by period relative to time in prison*

The rate of health care utilization was greater for persons in the prison release group than general population controls, both in prison and in the post-release periods, as shown in Fig. 2.

As shown in Table 2, adjustment for ADGs resulted in a substantial decrease in the ratio of primary care utilization rate for the prison release group compared to general population controls. However, there remained a significant positive association across time periods between imprisonment status and primary care utilization.

The proportion of people who accessed any primary care was significantly higher for those in the prison release group compared to general population controls for the periods in prison and post-release days 0-6, 7-29 and 30-89, as shown in Table 3. In contrast, the proportion that accessed any primary care was significantly greater for the general population compared to the prison release group for days 180-364 and 365-730 post-release.

Figure 3 shows the time to first use of primary care after release from prison to two years. By one month after release, $66.3 \%$ of women and $75.5 \%$ of men had not yet accessed primary care and by three months after release, $50.5 \%$ of women and $62.9 \%$ of men had not yet accessed primary care. By two years after release, $16.8 \%$ of women and $28.2 \%$ of men had not accessed primary care.

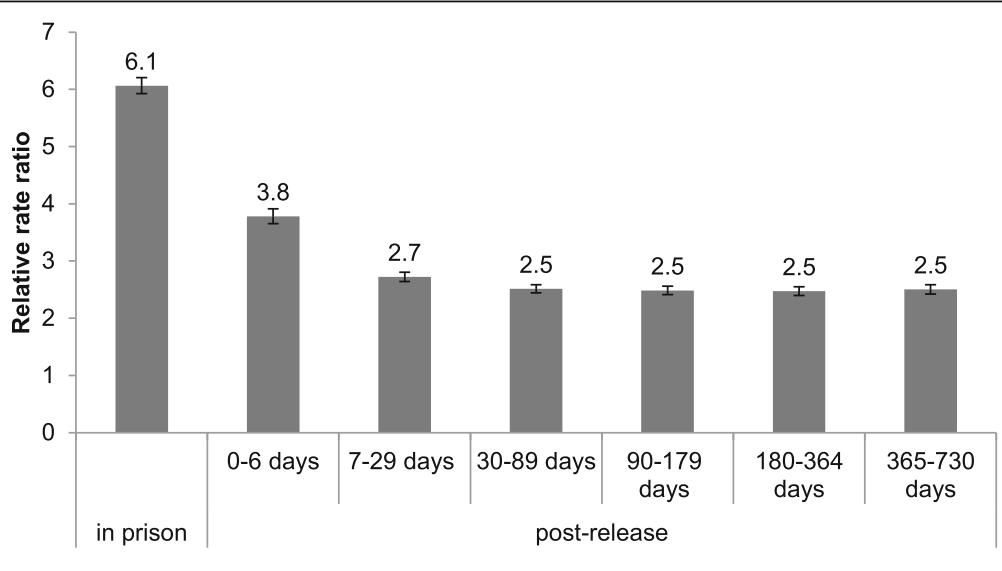

${ }^{*}$ Adjusted for neighbourhood income quintile and rurality. $†$ Or the corresponding period for general population controls.

Fig. 2 Relative rate ratio* of primary care utilization and 95\% confidence intervals for persons released from provincial prison in 2010 and age- and sex-matched general population controls in Ontario, Canada, by period relative to time in prisont 
Table 2 Unadjusted and adjusted rate ratio of primary care utilization for persons released from provincial prison in 2010 and ageand sex-matched general population controls in Ontario, Canada, by period relative to time in prison ${ }^{\text {a }}$

\begin{tabular}{lllll}
\hline $\begin{array}{l}\text { Period relative to } \\
\text { time in prison }\end{array}$ & $\begin{array}{l}\text { Unadjusted rate } \\
\text { ratio }(95 \% \mathrm{Cl})\end{array}$ & $\begin{array}{l}\text { Rate ratio adjusted for neighbourhood } \\
\text { income quintile and rurality }(95 \% \mathrm{Cl})\end{array}$ & $\begin{array}{l}\text { Rate ratio adjusted for neighbourhood } \\
\text { income quintile, rurality, and } \mathrm{ADGs}{ }^{\mathrm{b}}(95 \% \mathrm{Cl})\end{array}$ \\
\hline In prison & $6.1(5.9,6.2)$ & $6.1(5.9,6.2)$ & $3.9(3.8,4.0)$ \\
Post-release & $0-6$ days & $3.7(3.6,3.8)$ & $3.8(3.7,3.9)$ & $2.7(2.6,2.8)$ \\
& $7-29$ days & $2.6(2.6,2.7)$ & $2.7(2.6,2.8)$ & $1.9(1.9,2.0)$ \\
& $30-89$ days & $2.4(2.4,2.5)$ & $2.5(2.4,2.6)$ & $1.8(1.7,1.9)$ \\
& $90-179$ days & $2.4(2.3,2.5)$ & $2.5(2.4,2.6)$ & $1.8(1.7,1.9)$ \\
& 180-364 days & $2.4(2.4,2.5)$ & $2.5(2.4,2.5)$ & $1.8(1.8,1.9)$ \\
& $365-730$ days & $2.5(2.4,2.6)$ & $2.5(2.4,2.6)$ & $1.9(1.8,2.0)$ \\
\hline
\end{tabular}

${ }^{\mathrm{a}}$ Or the corresponding period for general population controls. ${ }^{\mathrm{b}} \mathrm{ADGs}$ Aggregated Diagnosis Groups

\section{Discussion}

This study identifies very high absolute and relative rates of primary care utilization in people who experience imprisonment, with over six-fold the primary care utilization rate in prison and more than twice the utilization rate post-release compared to general population controls. The associations did not change substantially after adjusting for neighbourhood income quintile and rurality, and the positive associations persisted after adjusting for comorbidity. In prison and in the months after release, a higher proportion of people in the prison release group accessed care compared to the general population controls for the same period. We note, however, that a substantial proportion of people in the prison release group did not access primary care in the months after release; more than half of women and more than $60 \%$ of men had not accessed primary care by three months post-release.

In prison, the rate of primary care utilization in our study was similar to rates in other studies, which were between 5 and 20 visits per year [7-12]. Regarding use of primary care after prison release, the proportion accessing primary care was higher in our study than in a sample of women leaving jail in New York City between 1997 to 2001, in which 47\% reported primary care use in the year post-release [15], and lower than in a study of persons released from prison in Australia, in which 43\% of men and $58 \%$ of women accessed care in the month post-release [5]. These differences may reflect differences in the health care system, for example the lack of a universal health insurance system may have contributed to lower primary care utilization in the New York City study. There is a paucity of available and comparable data on the proportion of persons accessing primary care in prison or on rates of primary care utilization post-release [14].

This study has limitations that may affect internal and external validity. We were not able to discern whether primary care visits in prison were for administrative reasons only, e.g. for ministry-required physician assessments, or whether ministry-required physician assessments were included in OHIP billings and therefore represented in health administrative data. We think it is unlikely that these issues would substantially alter our findings. We did not include primary care encounters in Community Health Centres, which provide primary care for an estimated $4 \%$ of the Ontario population [38] and about $5 \%$ of persons who experience imprisonment (data available from author on request). This exclusion would likely have

Table 3 Proportion of persons released from provincial prison in 2010 and age- and sex-matched general population controls in Ontario, Canada with any primary care utilization, by period relative to time in prison $^{\text {a }}$

\begin{tabular}{|c|c|c|c|c|c|}
\hline \multirow{2}{*}{$\begin{array}{l}\text { Period relative to } \\
\text { time in prison* }\end{array}$} & \multicolumn{2}{|c|}{ Prison release group } & \multicolumn{2}{|c|}{ General population controls } & \multirow[t]{2}{*}{$p$ value $\neq$} \\
\hline & $\bar{N}$ & Any use (\%) & $\bar{N}$ & Any use (\%) & \\
\hline In prison ${ }^{b}$ & 48,861 & $40.8 \%$ & 195,444 & $14.0 \%$ & $<0.001$ \\
\hline 0-6 days post-release & 48,861 & $13.4 \%$ & 195,444 & $4.4 \%$ & $<0.001$ \\
\hline 7-29 days post-release & 47,870 & $19.5 \%$ & 195,393 & $12.0 \%$ & $<0.001$ \\
\hline 30-89 days post-release & 44,939 & $28.5 \%$ & 195,231 & $24.2 \%$ & $<0.001$ \\
\hline 90-179 days post-release & 39,328 & $33.3 \%$ & 194,794 & $31.7 \%$ & $<0.001$ \\
\hline 180-364 days post-release & 33,538 & $43.9 \%$ & 194,158 & $47.3 \%$ & $<0.001$ \\
\hline 365-730 days post-release & 26,055 & $58.3 \%$ & 193,040 & $61.8 \%$ & $<0.001$ \\
\hline
\end{tabular}

${ }^{a}$ Or the corresponding period for general population controls. Note that the period lengths vary, which limits the ability to compare the percent with any use between time periods. ${ }^{\mathrm{b}}$ The median length of time in prison was 10 days (interquartile range 3 to 52 days). $\neq$ From chi squared test of the proportion with any use in the prison release group compared to general population controls 


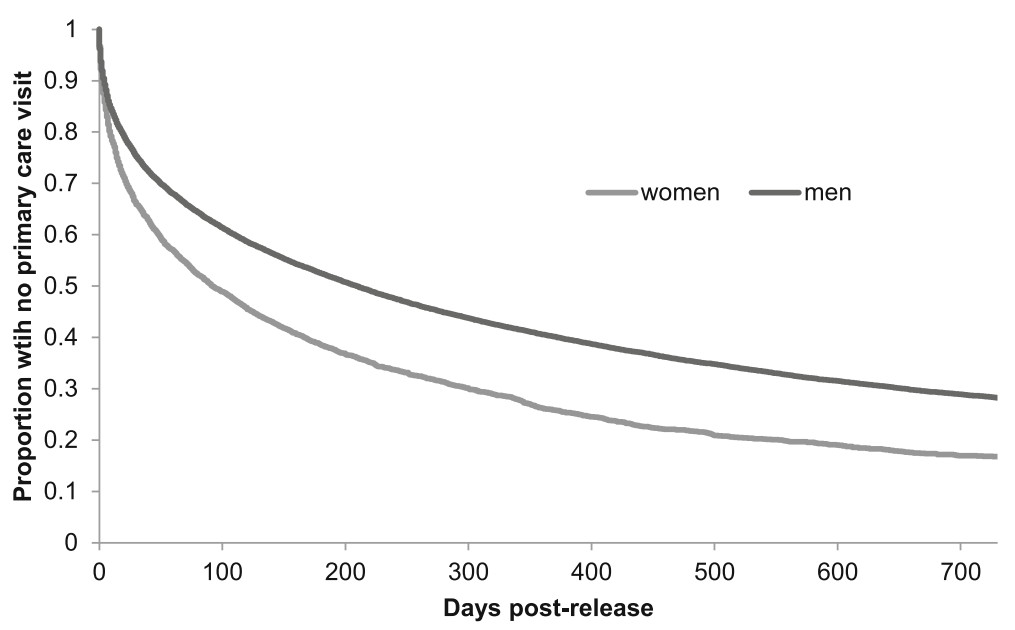

Fig. 3 Kaplan-Meier curve of time to primary care use post-release for persons released from provincial prison in 2010 in Ontario, Canada, by sex

led to a conservative bias in the relative rate ratios. A limitation due to the longitudinal nature of the study is that a substantial proportion of persons who were released in 2010 were not included in some follow up periods in the months after release due to right censoring as described in the analysis plan, such that by 6 months after release, only $68.6 \%$ of persons were still in the community (as per Table 3 ), largely due to readmission to prison. If utilization of primary care were associated with risk of readmission to prison, this could contribute to apparent differences in use over time. However, as the largest differences in rates of use occur between the time in prison and the immediate post-release period, by which time very little right censoring had occurred, we think it is unlikely that this would explain the general pattern of use by period post-release. Finally, the study results may not be generalizable to other jurisdictions, for example to jurisdictions with different healthcare systems (including those with no universal health insurance program), criminal justice systems, or prison environments, or in which patterns of morbidity and mortality differ in prison or general populations.

Various factors may contribute to the high rate of primary care utilization in this population, including increased comorbidity burden, increased injury and acute illness, and a low threshold for seeking care in prison. Data from our study and from previous reviews [3, 39] reveal high comorbidity in this population, which could lead to greater primary care use. However, even after controlling for ADGs, the positive association between imprisonment status and primary care utilization persisted. While ADGs have been shown to predict morbidity [40], mortality [33], and health care utilization, [41, 42] their validity as a comorbidity indicator has not been assessed in people who experience imprisonment; even after controlling for ADGs, there may be a residual effect of comorbidity. More complex models and more detailed data would be valuable to explore specific mechanisms in greater detail. The social and physical environment, as well as risk behaviours in prison and in the community may also increase the risk of injury or acute illness and stress in this population [8, 39, 43-46], which could contribute to primary care use. These factors would not be reflected in ADGs, which capture only current diagnoses and their sequelae. Other studies have suggested that increased primary care use in prison may reflect care seeking for issues that would be managed in the community without seeing a physician, for example through discussion with friends, family or a pharmacist [7], and that the low opportunity costs of seeing a physician in prison may encourage care use [10]. These factors may explain some of the difference in use in prison and post-release, but would not explain the increased use post-release compared to the general population.

While relative rates of health care utilization were consistently higher for the prison release group compared to general population controls, we note that only a minority of people in the prison release group accessed any primary care in the weeks after release. This is concerning given the high morbidity identified in this population in this study and others [3, 39], for which patients may need and want ongoing medical care, and given the high risk of adverse outcomes in the immediate post-release period [20,34-36]. Of note, the increased rate of primary care utilization for the prison release group in the week after release compared to later post-release periods could reflect people appropriately accessing primary care for continuity of care for ongoing medical and social issues or to address new issues associated with the transition back to the community. However, it could also signal a lack of attention to health needs prior to release, such as providing bridging medications or prescriptions. Other types of data, such as 
data from medical charts and interviews, would be required to elucidate the reasons for the difference in primary care utilization rates over the post-release period.

Further research should explore primary care use in this population, including reasons for seeking care in prison and after prison release, and care experiences including access to preventive care and quality of care. This work should be done in collaboration with affected populations including people with a lived experience of imprisonment. In parallel with research, we should advance work to improve appropriate access to and acceptability of primary health care for this population. Building on the limited evidence to date [4, 13, 47-50], interventions should focus on improving access to care and quality of health care in prison and post-release.

\section{Conclusions}

This large population-based study shows that people who experience imprisonment in Ontario, Canada have very high rates of primary care utilization compared to the general population. This association is only partly explained by increased comorbidity. Of note, a substantial proportion of people in the prison release group did not access primary care in the months after release. Research is required to understand the reasons for increased primary care utilization in this population and to support access to care for persons who are not accessing care post-release.

\section{Additional file}

Additional file 1: Flow chart for linkage of data. (DOCX $44 \mathrm{~kb}$ )

\section{Abbreviations}

ADGs: Aggregated Diagnosis Groups; CHF: Congestive heart failure; COPD: Chronic obstructive pulmonary disease; HIV: Human immunodeficiency virus; IQR: Interquartile range; MCSCS: Ministry of Community Safety and Correctional Services; MOHLTC: Ministry of Health and Long-Term Care; OHIP: Ontario Health Insurance Plan

\section{Acknowledgements}

This study was supported by ICES, which is funded by an annual grant from the Ontario Ministry of Health and Long-Term Care (MOHLTC). We acknowledge the Ontario Ministry of Community Safety and Correctional Services (MCSCS), which supported the study, and we appreciate the contributions of Mr. Michael Kirk.

The analyses, opinions, results and conclusions reported in this paper are independent from the other sources that provided data and funding. No endorsement by ICES, the MOHLTC, or the MCSCS is intended or should be inferred.

\section{Funding}

This study was funded by the Foundation for Advancing Family Medicine of the College of Family Physicians of Canada and the Physicians' Services Incorporated Foundation. The funding bodies had no role in the design of the study, in the collection, analysis, and interpretation of data, or in writing the manuscript.

\section{Availability of data and materials}

We are not able to share data because of restrictions specified in our Research Agreement with the Ministry of Community Safety and Correctional Services (MCSCS) and in the data sharing agreements of ICES. Persons who would like to request access to data from the MCSCS would need permission from the MCSCS, and should direct requests to Michael Kirk at michael.kirk@ontario.ca. Access to data at ICES can be granted to those who to meet pre-specified criteria for confidential access, available at www.ices.on.ca/. Requests to access ICES data for research purposes may be submitted to ICES' Data and Analytic Services, with information at http://www.ices.on.ca/DAS and contact: das@ices.on.ca.

\section{Authors' contributions}

All authors contributed to study design, assisted with data interpretation, revised the manuscript, and approved the final version. FGK conceptualized the study. FGK and SHM drafted the manuscript. SYC, KF, and FGK conducted analyses.

\section{Ethics approval and consent to participate}

The study was approved by the St. Michael's Hospital Research Ethics Board and the Hamilton Integrated Research Ethics Board. We did not obtain individual consent to participate, as we used administrative data, there was minimal risk involved, and it was not feasible to obtain consent.

\section{Consent for publication}

Not applicable.

\section{Competing interests}

The authors declare that they have no competing interests.

\section{Publisher's Note}

Springer Nature remains neutral with regard to jurisdictional claims in published maps and institutional affiliations.

\section{Author details}

${ }^{1}$ David Braley Health Sciences Centre, McMaster University, 5th Floor, 100 Main Street West, Hamilton, Ontario L8P1H6, Canada. ${ }^{2}$ St. Michael's Hospital, Toronto, Canada. ${ }^{3}$ ICES, Toronto, Canada. ${ }^{4}$ Faculty of Medicine, McMaster University, Hamilton, Canada. ${ }^{5}$ Schwartz/Reisman Emergency Medicine Institute, Sinai Health System, Toronto, Canada. ${ }^{6}$ Department of Family and Community Medicine, University of Toronto, Toronto, Canada. ${ }^{7}$ Dalla Lana School of Public Health, University of Toronto, Toronto, Canada. ${ }^{8}$ C.T. Lamont Primary Health Care Research Group, Bruyère Research Institute, Ottawa, Canada. ${ }^{9}$ Department of Family Medicine, University of Ottawa, Ottawa, Canada. ${ }^{10}$ Ontario Ministry of Community Safety and Correctional Services, Toronto, Canada. ${ }^{11}$ Centre for Criminology and Sociolegal Studies, University of Toronto, Toronto, Canada.

Received: 25 June 2018 Accepted: 29 October 2018

Published online: 09 November 2018

References

1. Walmsley R. World prison population list, 11th edition: King's College London International Centre for Prison Studies; 2016.

2. Kinner SA, Forsyth S, Williams G. Systematic review of record linkage studies of mortality in ex-prisoners: why (good) methods matter. Addiction. 2013; 108(1):38-49. https://doi.org/10.1111/add.12010 [published Online First: 2012/11/21].

3. Fazel S, Baillargeon J. The health of prisoners. Lancet. 2011;377(9769):956-65 doi: S0140-6736(10)61053-7 [pii] 10.1016/S0140-6736(10)61053-7 [published Online First: 2010/11/26]

4. Wang EA, Hong CS, Shavit S, et al. Engaging individuals recently released from prison into primary care: a randomized trial. Am J Public Health. 2012; 102(9):e22-9. https://doi.org/10.2105/AJPH.2012.300894.

5. Young JT, Arnold-Reed D, Preen D, et al. Early primary care physician contact and health service utilisation in a large sample of recently released ex-prisoners in Australia: prospective cohort study. BMJ Open. 2015;5(6): e008021. https://doi.org/10.1136/bmjopen-2015-008021 [published Online First: 2015/06/13].

6. United Nations. The United Nations Standard Minimum Rules for the Treatment of Prisoners (the Nelson Mandela Rules) Geneva, Switzerland 
2015 [Available from: https://www.unodc.org/documents/justice-and-prisonreform/GA-RESOLUTION/E_ebook.pdf].

7. Feron JM, Paulus $D$, Tonglet $R$, et al. Substantial use of primary health care by prisoners: epidemiological description and possible explanations. J Epidemiol Community Health. 2005;59(8):651-5. https://doi.org/10.1136/jech. 2004.022269 [published Online First: 2005/07/16].

8. Sheps SB, Schechter MT, Prefontaine RG. Prison health services: a utilization study. J Community Health. 1987;12(1):4-22.

9. Moschetti K, Zabrodina V, Stadelmann P, et al. Exploring differences in healthcare utilization of prisoners in the Canton of Vaud, Switzerland. PLoS One. 2017;12(10):e0187255. https://doi.org/10.1371/journal.pone.0187255 [published Online First: 2017/10/31].

10. Marshall T, Simpson S, Stevens A. Use of health services by prison inmates: comparisons with the community. J Epidemiol Community Health. 2001; 55(5):364-5 [published Online First: 2001/04/12].

11. A health care needs assessment of federal inmates in Canada. Canadian journal of public health = Revue canadienne de sante publique 2004:95 Suppl 1:59-63.

12. Nobile CG, Flotta D, Nicotera G, et al. Self-reported health status and access to health services in a sample of prisoners in Italy. BMC Public Health. 2011;11:529. https://doi.org/10.1186/1471-2458-11-529 [published Online First: 2011/07/06].

13. Kinner $S A$, Alati $R$, Longo $M$, et al. Low-intensity case management increases contact with primary care in recently released prisoners: a single-blinded, multisite, randomised controlled trial. J Epidemiol Community Health. 2016;70(7):683-8. https:/doi.org/10.1136/jech-2015-206565 [published Online First: 2016/01/21].

14. Wilper AP, Woolhandler S, Boyd JW, et al. The health and health care of US prisoners: results of a nationwide survey. Am J Public Health. 2009;99(4): 666-72. https://doi.org/10.2105/AJPH.2008.144279.

15. Lee J, Vlahov D, Freudenberg N. Primary care and health insurance among women released from New York City jails. J Health Care Poor Underserved. 2006;17(1):200-17. https://doi.org/10.1353/hpu.2006.0028.

16. Mallik-Kane K, Visher CA. Health and Prisoner Reentry: How Physical, Mental, and Substance Abuse Conditions Shape the Process of Reintegration. Washington, DC: Urban Institute Justice Policy Center; 2008.

17. Mallik-Kane K. Returning Home Illinois Policy Brief: Health and Prisoner Reentry. Washington, DC: Urban Institute Justice Policy Center; 2005.

18. Reitano J. Adult correctional statistics in Canada, 2015/2016. 2017 [Available from: http://www.statcan.gc.ca/pub/85-002-x/2017001/article/14700-eng.htm].

19. Government of Ontario. Apply for OHIP and get a health card 2017 [Available from: https://www.ontario.ca/page/apply-ohip-and-get-health-card - section-0].

20. Kouyoumdjian FG, Cheng SY, Fung $\mathrm{K}$, et al. The health care utilization of people in prison and after prison release: A population-based cohort study in Ontario, Canada. PLoS One. 2018;13(8):e0201592. https://doi.org/10.1371/ journal.pone.0201592 [published Online First: 2018/08/04]

21. Chong N. IARC Technical Reports No. 32: Automated Data Collection in Cancer Registration: Computerized record linkage in cancer registries. In: International Agency for Research on Cancer. Lyon, France: World Health Organization; 1998.

22. Blackwell DL, Martinez ME, Gentleman JF, et al. Socioeconomic status and utilization of health care services in Canada and the United States: findings from a binational health survey. Med Care. 2009:47(11):1136-46. https://doi. org/10.1097/MLR.0b013e3181adcbe9.

23. Fitzpatrick T, Rosella LC, Calzavara A, et al. Looking Beyond Income and Education: Socioeconomic Status Gradients Among Future High-Cost Users of Health Care. Am J Prev Med. 2015. https://doi.org/10.1016/.jamepre.2015.02.018.

24. Morgenstern $\mathrm{H}$, Winn DM. A method for determining the sampling ratio in epidemiologic studies. Stat Med. 1983;2(3):387-96 [published Online First: 1983/07/01]

25. Hux JE, Ivis F, Flintoft $V$, et al. Diabetes in Ontario: determination of prevalence and incidence using a validated administrative data algorithm. Diabetes Care. 2002;25(3):512-6 [published Online First: 2002/03/05].

26. Tu K, Campbell NR, Chen ZL, et al. Accuracy of administrative databases in identifying patients with hypertension. Open Med. 2007;1(1):e18-26 [published Online First: 2007/01/01].

27. Gershon AS, Wang C, Guan J, et al. Identifying patients with physiciandiagnosed asthma in health administrative databases. Can Respir J. 2009; 16(6):183-8 [published Online First: 2009/12/17].

28. Gershon AS, Wang C, Guan J, et al. Identifying individuals with physcian diagnosed COPD in health administrative databases. COPD. 2009;6(5):38894 [published Online First: 2009/10/30].

29. Schultz SE, Rothwell DM, Chen Z, et al. Identifying cases of congestive heart failure from administrative data: a validation study using primary care patient records. Chronic Dis Inj Can. 2013;33(3):160-6 [published Online First: 2013/06/06].
30. Antoniou T, Zagorski B, Loutfy MR, et al. Validation of case-finding algorithms derived from administrative data for identifying adults living with human immunodeficiency virus infection. PLoS One. 2011;6(6):e21748. https://doi.org/ 10.1371/journal.pone.0021748 [published Online First: 2011/07/09].

31. Institute for Clinical Evaluative Sciences. Mental Health and Addictions System Performance in Ontario: A Baseline Scorecard: Technical Appendix 2018 [Available from: https://www.ices.on.ca/Publications/Atlases-andReports/2018/MHASEF].

32. ACG Johns Hopkins. The Johns Hopkins ACG System 2018 [Available from: https://www.hopkinsacg.org/].

33. Austin $P C$, van Walraven $C$, Wodchis WP, et al. Using the Johns Hopkins Aggregated Diagnosis Groups (ADGs) to predict mortality in a general adult population cohort in Ontario, Canada. Med Care. 2011;49(10):932-9. https:// doi.org/10.1097/MLR.0b013e318215d5e2.

34. Binswanger IA, Stern MF, Deyo RA, et al. Release from prison--a high risk of death for former inmates. N Engl J Med. 2007;356(2):157-65. https://doi.org/ 10.1056/NEJMsa064115.

35. Wang EA, Wang Y, Krumholz HM. A high risk of hospitalization following release from correctional facilities in Medicare beneficiaries: a retrospective matched cohort study, 2002 to 2010. JAMA Intern Med. 2013;173(17):16218. https://doi.org/10.1001/jamainternmed.2013.9008.

36. Kouyoumdjian F, Kiefer L, Wobeser W, Hwang SW. High mortality over 12 years of follow up in people admitted to provincial custody in Ontario: A retrospective cohort study. Can Med Assoc J Open. 2016:4(2):E153-E61.

37. Rothman KJ, Greenland S, Lash TJ. Modern Epidemiology. 3rd edition ed. Philadelphia, PA: Lippincott Williams \& Wilkins; 2008.

38. Office of the Auditor General of Ontario. 2017 Annual Report Toronto, Ontario2017 [Available from: http://www.auditor.on.ca/en/content/ annualreports/arreports/en17/v1_303en17.pdf].

39. Kouyoumdjian F, Schuler A, Matheson Fl, Hwang SW. The health status of prisoners in Canada: A narrative review. Can Fam Physician. 2016;62(3):215-22.

40. Austin PC, Stanbrook MB, Anderson GM, et al. Comparative ability of comorbidity classification methods for administrative data to predict outcomes in patients with chronic obstructive pulmonary disease. Ann Epidemiol. 2012;22(12):881-7. https://doi.org/10.1016/j.annepidem.2012.09. 011 [published Online First: 2012/11/06]

41. Brilleman SL, Gravelle H, Hollinghurst S, et al. Keep it simple? Predicting primary health care costs with clinical morbidity measures. J Health Econ. 2014;35:109-22. https://doi.org/10.1016/j.jhealeco.2014.02.005 [published Online First: 2014/03/25]

42. Fredriksson $M$, Edenström $M$, Lundahl $A$, Björkman L. Lakartidningen. [ACG model can predict large consumers of health care. Health care resources can be used more wisely, individuals at risk can receive better care]. 2015;112.

43. Sung HE. Prevalence and risk factors of violence-related and accident-related injuries among state prisoners. J Correct Health Care. 2010;16(3):178-87. https:// doi.org/10.1177/1078345810366287 [published Online First: 2010/05/15].

44. Henning J, Frangos S, Simon R, et al. Patterns of traumatic injury in New York City prisoners requiring hospital admission. J Correct Health Care. 2015; 21(1):53-8. https://doi.org/10.1177/1078345814558046 [published Online First: 2015/01/07].

45. Bick JA. Infection control in jails and prisons. Clin Infect Dis. 2007;45(8):104755. https://doi.org/10.1086/521910 [published Online First: 2007/09/21].

46. Massoglia M. Incarceration as exposure: the prison, infectious disease, and other stress-related illnesses. J Health Soc Behav. 2008;49(1):56-71. https:// doi.org/10.1177/002214650804900105 [published Online First: 2008/04/19]

47. Wang EA, White MC, Jamison R, et al. Discharge planning and continuity of health care: findings from the San Francisco County Jail. Am J Public Health. 2008;98(12):2182-4. https://doi.org/10.2105/AJPH.2007.119669 [published Online First: 2008/04/03]

48. Binswanger IA, Whitley E, Haffey PR, et al. A patient navigation intervention for drug-involved former prison inmates. Subst Abus. 2015;36(1):34-41. https://doi.org/10.1080/08897077.2014.932320 [published Online First: 2014/ 06/25].

49. Shaw J, Conover S, Herman D, et al. Critical time Intervention for Severely mentally ill Prisoners (CrISP): a randomised controlled trial. Southampton (UK)2017.

50. Lehman Held M, Brown CA, Frost LE, Hickey JS, Buck DS. Integrated Primary and behavioral health care in patient-centered medical homes for jail releasees with mental illness. Crim Justice and Behav. 2012;39(4):533-51. 